\title{
O COORDENADOR PEDAGÓGICO E AS ESCOLAS DE TEMPO INTEGRAL: A PESQUISA NO CONTEXTO DO SISTEMA MUNICIPAL DE ENSINO EM ARAÇATUBA
}

\author{
Raquel Pozzenato Silazaki, Renata Portela Rinaldi \\ Universidade Estadual Paulista - UNESP, Programa de Pós Graduação em Educação, Presidente Prudente, SP. E-mail: \\ rpsilazaki@hotmail.com
}

\begin{abstract}
RESUMO
Este trabalho visa apresentar a pesquisa desenvolvida no Programa de Pós-Graduação em Educação da FCT-UNESP/Presidente Prudente. Investigou as ações/atuação dos Coordenadores Pedagógicos do Ensino Fundamental I, do Sistema Municipal de Ensino de Araçatuba-SP, especificamente das Escolas de Tempo Integral e de Atividades Complementares. Focalizou as concepções acerca da formação desses profissionais e os desafios pertinentes à sua prática. Promoveu uma ação de formação continuada, modalidade aperfeiçoamento, sendo parte do processo de coleta de dados. De abordagem qualitativa, desenvolveu-se via pesquisa bibliográfica, documental e pela coleta de dados, pautada na perspectiva construtivo-colaborativa (COLE; KNOWLES, 1993) de pesquisa-intervenção. Participaram sete Coordenadores Pedagógicos, de cinco escolas. A análise foi orientada pela análise de conteúdo. Como resultados constatamos um contexto marcado por desafios administrativos e pedagógicos. Concluímos pela intervenção sobre essas questões e pela consolidação de uma Política Pública de Estado no município e uma Política de Formação Continuada aos Coordenadores dessas escolas.
\end{abstract}

Palavras-chave: Formadores de Professores da Educação Básica. Coordenação Pedagógica. Aprendizagem Profissional da Docência. Educação Integral. Escola com Jornada Ampliada.

\section{THE PEDAGOGICAL CORDINATOR AND FULL TIME SCHOOLS: THE RESEARCH IN THE CONTEXT OF THE MUNICIPAL SYSTEM OF EDUCATION IN ARAÇATUBA}

\begin{abstract}
This paper aims to present the research developed at Postgraduate Program in Education of FCTUNESP/Presidente Prudente. Investigated the actions /performance of the Pedagogical Coordinators in Elementary Schools from the Public-School System in Araçatuba City, specifically, the full-time and complementary activity public schools. It focused the conceptions about the formation of these professionals and the challenges pertinent to their practice. It promoted an action of continuous formation, modality improvement, being part of the process of data collect. From a qualitative approach, it was developed through bibliographical, documentary and data collect, based on the constructive-collaborative (COLE; KNOWLES, 1993) perspective of intervention research. Seven Pedagogical Coordinators from five schools had participated. The analysis was guided by the content analysis. The results show a context marked by administrative and pedagogical challenges. We had concluded by intervention on these issues and by consolidation of the State Public Policy in the municipality and a Continuing Education Policy to the Coordinators of these schools.
\end{abstract}

Keywords: Teacher's Formers in Basic Education. Pedagogical Coordination. Professional Learning of Teaching. Full-time Education. Extended Hours' Schools 


\section{INTRODUÇÃO}

Em contextos de mudanças e contingências que emergem em todos os setores, a sociedade atual exige, cada vez mais, que o cidadão reaja em seu meio e se posicione mediante às questões que sucateiam direitos, que ludibriam as grandes massas e que desconsideram as instituições representativas da sociedade, sejam elas de quais seguimentos forem. As mudanças são frutos do processo evolutivo, da dinâmica globalizante social, que coloca numa grande engrenagem a política, a economia, a justiça, a lei, o desenvolvimento da cultura e, dentre as "peças" desta grande "máquina", temos a educação. Acredita-se que, por essa via, possamos dar sustentação ao desenvolvimento de um país, ressignificando as bases de uma sociedade que evolui, mas que precisa saber onde quer chegar, sem ser manipulada e corrompida, a ponto de observarmos direitos fundamentais (individuais e coletivos) de uma nação serem colocados à prova, quando interesses escusos são colocados em prática.

Convivemos com essas situações, mas elas não podem prosperar. Na educação ao percebermos avanços e retrocessos, não podemos perder de vista o contexto escolar, os alunos e seus profissionais. A evolução social, que coloca para a educação perspectivas diferenciadas, requer que cada profissional assuma seus compromissos e se situe mediante este cenário de uma educação que já não se encontra, exclusivamente, centrada na escola. Essa percepção, ou mesmo a constatação de que outros meios, além do ensino formal, são capazes de gerar conhecimentos, exige que o profissional esteja atento para lidar (com) e educar a atual e as futuras gerações.

Neste contexto, que é complexo e exige posturas diferenciadas, trazemos algumas interfaces da pesquisa desenvolvida em Araçatuba, município do interior do estado de São Paulo, que envolveu os Coordenadores Pedagógicos $(\mathrm{COP})^{1}$ que atuam no âmbito de um "novo modelo de escola" ainda em construção no Sistema Municipal de Ensino: a Escola de Tempo Integral (ETI) ${ }^{2}$ e a escola com Atividades Complementares $(A C)^{3}$. Desenvolveu-se no interior da linha de pesquisa "Formação dos Profissionais da Educação, Políticas Educativas e Escola Pública" do Programa de Pós-Graduação em Educação da Faculdade de Ciências e Tecnologia, UNESP/Presidente Prudente. Investigou as ações voltadas à formação continuada e à atuação dos CoP do Ensino Fundamental I e focalizou as concepções acerca da formação desses profissionais, compreendidos por nós como formadores de professores da Educação Básica (RINALDI, 2009) e sobre os desafios pertinentes à sua prática neste complexo processo de implementação dessas escolas no sistema municipal.

Frente à percepção de que os CoP das escolas ETI e das escolas com AC, apresentavam diversos desafios na execução de suas atribuições nesse cenário de escolas, desde questões relacionadas à identidade profissional e ao próprio desenvolvimento profissional, que nos conduziu à necessidade de levantar e compreender algumas possíveis inconsistências acerca do desenvolvimento de suas ações no local de trabalho que, mesmo inseridos em processos formativos oferecidos pela Secretaria Municipal de Educação, davam indícios da falta de clareza de papéis, a dificuldade de atuar com os professores, sobretudo, nos processos de formação continuada e na condução da proposta pedagógica da escola. Desta forma, vimos a necessidade de aproximarmos o olhar para constatar, o que de fato movia as ações desses CoP, sobretudo, com a reponsabilidade pela oferta de uma educação integral ao aluno, que o coloque frente à essa sociedade em constante evolução e que possa lhe garantir o desenvolvimento humano, o pensamento crítico, sua evolução nos aspectos social, cultural, tecnológico etc., condições para que possa fazer frente às demandas deste mundo contemporâneo.

Assim, perpassando pelo crescente desenvolvimento desse Sistema Municipal de Ensino, pautado pelas exigências legais e estruturais necessárias à oferta do ensino, que seguiram avançando ao longo das últimas décadas do século passado até o momento atual, vimos o

\footnotetext{
${ }^{1}$ CoP, será usado no corpo deste texto, para denominar o Coordenador Pedagógico.

2 ETI, para Escola de Tempo Integral.

${ }^{3} \mathrm{AC}$, para escolas com Atividades Complementares.
} 
município assumir a responsabilidade pelas ETI/AC, desafiando toda ordem de capacidade em termos técnicos e pedagógicos, conhecimento e manejo para seu gerenciamento. Dentre os profissionais responsáveis por assumirem essas escolas destacamos, na investigação realizada, o CoP.

Ressaltamos, que este sistema de ensino conta com 64 unidades escolares, sendo: 04 com Educação Infantil e Ensino Fundamental, oferecidos concomitantemente; 36 de Educação Infantil; 24 de Ensino Fundamental. Dessas 24, temos, atualmente, 11 escolas que são ETI ou de AC. À época do desenvolvimento da pesquisa (de 2015, à início de janeiro de 2017) tínhamos apenas 10. Neste ano letivo, implantou-se a décima primeira. Elas estão classificadas no quadro 1, de acordo com sua natureza.

Quadro 1. Natureza das ETI/AC participantes.

\begin{tabular}{|l|l|}
\hline \multicolumn{1}{|c|}{$\begin{array}{c}\text { Modelos de ETI/AC e no de } \\
\text { unidades }\end{array}$} & \multicolumn{1}{c|}{ Natureza/características } \\
\hline $\begin{array}{l}\text { Escola de Tempo Integral (ETI) } \\
\text { - oito un. }\end{array}$ & $\begin{array}{l}\text { Escolas estaduais, advindas no processo de municipalização. Processo que ocorreu } \\
\text { em etapas. Na terceira e última fase, em 2007, o município recebeu 4 unidades de } \\
\text { jornada integral (ensino regular e oficinas curriculares) para todos os alunos. } \\
\text { Escolas que, a princípio, tinham suas concepções pedagógicas centradas na } \\
\text { regulamentação estadual (Resolução no 89 de 09/12/2005). }\end{array}$ \\
\hline $\begin{array}{l}\text { Escola com Atividade } \\
\text { Complementar-(AC) - três un. }\end{array}$ & $\begin{array}{l}\text { Escolas com a ampliação da jornada no contraturno, somente para alguns alunos } \\
\text { da unidade escolar, nos dois períodos, manhã ou tarde. }\end{array}$ \\
\hline
\end{tabular}

Fonte: Elaboração própria com base na pesquisa desenvolvida.

A partir dessa estrutura, no início da pesquisa, tínhamos a previsão de atuar com treze CoP, que correspondia ao número total desses profissionais atuantes nas ETI/AC. Um CoP, recusou participar por compromissos pessoais, mas todos os demais aceitaram o convite. Fechamos com um total de doze CoP, de dez unidades escolares. Ao final da pesquisa e do curso de formação continuada oferecido, tínhamos sete participantes, de cinco escolas. A evasão ocorreu por motivos e em momentos diversos, conforme se observa no quadro 2 :

Quadro 2. Desistência de cursistas, momento de saída e motivos/causas.

\begin{tabular}{|c|c|c|c|c|}
\hline $\begin{array}{c}\text { № de } \\
\text { desistentes }\end{array}$ & CoP/Gestor & $\begin{array}{l}\text { UE/modelo } \\
\text { de ETI }\end{array}$ & Momento da saída & Motivos/Causas \\
\hline 1 & CoP 2 & ETI & $\begin{array}{l}\text { Faltou no } 1 \text { o encontro } \\
\text { e desistiu } 3 \text { o encontro }\end{array}$ & Doença com tratamento prolongado \\
\hline 2 & CoP 5 & $A C$ & $\begin{array}{l}\text { Faltou no } 10 \text { encontro } \\
\text { e desistiu no } 30 \\
\text { encontro }\end{array}$ & $\begin{array}{l}\text { Motivos pessoais e por entender que sua } \\
\text { realidade em nada se caracteriza com a } \\
\text { AC. }\end{array}$ \\
\hline 3 & CoP 6 & AC & 7으 encontro & $\begin{array}{l}\text { Doença, cirurgia e tratamento } \\
\text { prolongado. }\end{array}$ \\
\hline 4 & CoP 9 & $A C$ & Não iniciou o curso & $\begin{array}{l}\text { Falta de funcionários na escola para cobrir } \\
\text { a saída de alunos para que pudesse } \\
\text { frequentar o curso. }\end{array}$ \\
\hline 5 & CoP 12 & $A C$ & 30 encontro & $\begin{array}{l}\text { Falta de identificação com o grupo de } \\
\text { profissionais e por entender que sua } \\
\text { realidade em nada se caracteriza com a } \\
\text { AC. }\end{array}$ \\
\hline
\end{tabular}

Fonte: Elaboração própria com base na pesquisa desenvolvida.

Neste sentido, para o presente texto, temos como objetivo compreender as concepções acerca da formação dos CoP e os desafios pertinentes à sua prática nas ETI/AC. Um contexto escolar diferenciado que, embora, tenha implantado a jornada ampliada na última fase do convênio de municipalização com o Estado, em 2007, ainda enfrenta desafios de toda ordem. É 
certo que foram inúmeros os avanços na oferta do ensino, mas as ETI/AC encontram-se, ainda, em processo evolutivo no município. Com isso, temos a figura do CoP, profissional que buscamos analisar sob a ótica de sua formação pessoal/acadêmica; sob os contextos de formação continuada oferecidos pela Secretaria de Educação, observando se esses contextos formativos contribuíam para responder às demandas e complexidades que emergem nos âmbito dessas escolas; se eles se reconheciam (ou não) como formadores de professores da Educação Básica (RINALDI, 2009); sobre as dificuldades para organizar os processos formativos com os professores das ETI/AC e que de formas buscavam superá-las.

\section{METODOLOGIA}

A pesquisa qualitativa direcionou os caminhos percorridos, tendo sido compreendida como um processo que marcou a interação entre pesquisador e pesquisados quanto ao conhecimento que se construiu em torno da temática. Pautou-se nessa vertente e percorreu uma trajetória para descobrir o sentido conferido às funções e atribuições do CoP, sobretudo, em relação aos processos formativos pelos quais esse profissional se torna responsável quando assume a função da coordenação pedagógica, os desafios presentes no cotidiano da escola e que revelam a necessidade de buscar caminhos mais profícuos para a sua trajetória (do CoP) nas ETI/AC.

Com o objetivo de ampliar e aperfeiçoar o conhecimento dos envolvidos, compreendemos que a pesquisa não se faz no isolamento. Mais do que constatar, provar e testar foi necessário compreender o contexto em que ela estava inserida, percebê-la como um processo dinâmico e assim interpretar seus fenômenos, com todos os envolvidos. Com isso, a pesquisa qualitativa [...] "busca dar sentido aos significados dos fenômenos que ocorrem por meio dos fatos e locais que constituem seus objetos". (CHIZZOTTI, 2003. p. 221).

Destacamos, o compromisso ético assumido com os participantes e o Comitê de Ética em Pesquisa com Seres Humanos (CAAE 53868316.6.0000.5402), percorrendo um processo de interação contínua, onde os aspectos levantados pelos participantes eram todos considerados importantes. Visamos observar o que Godoy $(1995$, p. 63) preceitua:

Os pesquisadores qualitativos tentam compreender os fenômenos que estão sendo estudados a partir da perspectiva dos participantes. Considerando todos os pontos de vista como importantes, este tipo de pesquisa "ilumina", esclarece o dinamismo interno das situações, frequentemente invisível para observadores externos [...].

A interação e a compreensão das realidades vividas pelos CoP nesta pesquisa ocorreram de uma forma dialógica, de modo que pesquisador e pesquisados, compartilhassem saberes na vertente construtivo-colaborativa (COLE; KNOWLES, 1993; RINALDI 2009), de pesquisaintervenção, para que todos pudessem se apoderar da realidade vivida nas ETI/AC e nelas intervir num processo de desenvolvimento profissional.

Intrínseco a esse processo, perpassamos pela pesquisa bibliográfica, que nos permitiu ampliar os conhecimentos em torno da temática, além disso perceber os diversos enfoques que permeiam a produção acadêmica/científica, permitindo-nos a construção de novos conhecimentos. A pesquisa documental balizou o entendimento, sobretudo, para compreender quem é este profissional, o CoP. Por fim, a coleta de dados, por meio do trabalho empírico, vindo a se formalizar por meio de um curso de formação continuada oferecido aos CoP, pela aplicação do grupo dialogal e do questionário que levantou aspectos relacionados à formação acadêmica, atuação profissional e sobre questões que os envolviam no cotidiano escolar. Todos os encontros de formação (total de dez) que ocorreram com esse grupo de profissionais, foram filmados e transcritos com base no protocolo NURK. 
Para que esse processo de descoberta se tornasse evidente, as análises sobre a coleta de dados empíricos foram orientadas à luz da análise de conteúdo, momento em que foram levantadas as categorias e subcategorias de análises, trilhando um caminho de significados apoiado [...] "numa concepção de ciência que reconhece o papel ativo do sujeito na produção do conhecimento" (FRANCO, 2012, p.10).

Perpassamos pelo processo de aprofundamento e observação intensa das categorias e subcategorias levantadas, foram elas: Identidade Profissional do CoP Formador de Professor da Educação Básica; Sentimento de impotência, de falta de preparo profissional; A necessidade de formação continuada no âmbito da Secretaria de Educação; Ausência de ações por parte da SE para contribuir com as ações do CoP na ETI/AC; Desafios (ações/práticas) que ainda precisam ser trabalhados pelo CoP nas ETI/AC; A formação continuada no âmbito das escolas de ETI/AC; O CoP Formador de Professor da Educação Básica; Alguns aspectos dificultadores para o desenvolvimento da formação continuada na escola; Condições de trabalho (falta de infraestrutura e profissionais). Foi um processo que nos levou abstrair o sentido das manifestações dos coordenadores, a fazer inferências e a produzir conhecimento sobre o contexto que a pesquisa se desenvolve, ou seja, nas ETI/AC do município de Araçatuba.

\section{RESULTADOS}

Com base nos objetivos estabelecidos na pesquisa e na análise das categorias/ subcategorias buscamos construir conhecimentos pautados no exercício da reflexão, no planejamento e no encaminhamento de ações para dar efetividade à uma escola de tempo integral para uma educação integral, compromissada com a oferta de uma educação pautada na emancipação dos alunos e na oferta de uma educação de qualidade. Brevemente, tivemos os seguintes resultados: os CoP se reconhecem como formadores de professores em "processo" nas ETI/AC. E, mesmo aquele que se reconhece formador de professor, fragiliza-se quando reconhece que não consegue atingir os objetivos, ou desenvolver um trabalho profícuo de formação com os professores ou com os estagiários das oficinas curriculares; compreendem necessária a formação continuada dos professores e reconhecem a escola como local privilegiado para que a formação aconteça; se responsabilizam pela formação continuada com os professores, mas: prevalece estudos centrados na leitura de livros, textos, visualização de vídeos, trocas de experiências, abordagem de temas e assuntos propostos pela SME (de caráter geral) e fica em segundo plano, a formação que atenda às necessidades geradas nessa realidade de escolas e os aspectos relacionados às dificuldades enfrentadas na mediação do professor com os alunos; convivem com a falta de formação, oferecida pela Secretaria de Educação, exclusiva para o CoP, formador de professor da Educação Básica, para que ele amplie suas capacidades formativas junto a seus professores; há a falta de formação específica, oferecida pela Secretaria de Educação para a realidade da escola de tempo integral, para uma educação integral; convivem com a necessidade do município, na pessoa de seus gestores educacionais e demais administradores discutirem, analisarem, refletirem e investirem, específica e adequadamente na política da escola de tempo integral para uma educação integral; os CoP mostram-se abertos à processos formativos, expressam a vontade de melhorarem suas práticas, se responsabilizam pelo funcionamento dessas escolas, ainda que haja pouco apoio institucional para essas escolas.

\section{DISCUSSÕES}

Visualiza-se, portanto, que ainda é necessário que o CoP amplie sua consciência em torno de sua identidade profissional e de sua constituição como formador de professor, como uma atitude intrínseca à sua prática. Rinaldi (2009, p. 30) conceitua:

[...] são formadores de professores todos os profissionais que atuam na educação básica e são responsáveis pelo processo formativo dos 
professores dos anos iniciais no ambiente escolar, especificamente me refiro à: diretor, coordenador pedagógico, assistente técnico pedagógico, supervisores de ensino, entre outros.

No contexto das ETI/AC, o CoP é o maior responsável pela formação na escola e foi possível observar, a fragilidade com que esse profissional lida com sua própria identidade profissional, com sua constituição como formador de professor. Por isso, é preciso que sejam oferecidas condições específicas de formação continuada, de modo que se ele identifique nesse processo e possa intervir nessas realidades. Segundo Imbernón (2010, p. 9), [...] "não podemos separar a formação do contexto de trabalho, porque nos enganaríamos em nosso discurso" [...]. O contexto condicionará as práticas formadoras, bem como a sua repercussão nos professores e, também, na inovação e na mudança. Ademais, deve avançar na constituição da identidade profissional, com o objetivo de aprimorar a profissionalização, pois é necessário que este profissional seja reconhecido no âmbito deste sistema de ensino, mas, acima de tudo, também se reconheça como parte de uma categoria de profissionais com papéis significativos a serem desenvolvidos no coletivo escolar. Aprimorar, também, sua profissionalidade, que diz respeito aos conhecimentos e habilidades necessárias ao exercício profissional, para assim, agir na solução das dificuldades e desafios do ensino.

\section{CONCLUSÃO}

Os indicativos desta pesquisa realizada, se revelaram como uma necessidade de ampliar o debate em torno das políticas públicas de Educação Básica em todos os níveis e modalidades de ensino oferecidos no Sistema Municipal de Ensino em Araçatuba e que possamos, continuamente, evoluir para a oferta de uma educação de qualidade e emancipatória. É necessário que todos (administradores, formadores da educação básica, conselhos escolares, professores, estudantes, pais, comunidade etc.) contribuam com esse processo e que o CoP tenha a correspondente valorização, formação e acompanhamento profissional que o sustente no desenvolvimento de seu trabalho nas ETI/AC, visando, com isso, oferecer um ensino condizente com essa sociedade evolutiva e que requer pessoas capazes de intervir positivamente em seus contextos de atuação.

\section{REFERÊNCIAS}

COLE, L.; KNOWLES, J. G. Teacher Development partnership research: a focus on methods and issues. American Educational Reasearch Journal, v. 30, n. 3, 1993, p. 473-495, https://doi.org/10.3102/00028312030003473.

SILAZAKI, R. P. O processo de aprendizagem profissional de coordenadores pedagógicos para as/ nas escolas de/em tempo integral no município de Araçatuba. 2017. 259 f. Dissertação (Mestrado em Educação) - Universidade Estadual Paulista (UNESP), Faculdade de Ciências e Tecnologia, Presidente Prudente.

CHIZZOTTI, A. A pesquisa qualitativa em ciências humanas e sociais: evolução e desafios. Revista Portuguesa de Educação, v. 16, n. 2, 2003, p. 221-236. Universidade do Minho Braga, Portugal. Disponível em: < http://www.redalyc.org/articulo.oa?id=37416210> Acesso em: 05 ago. 2017.

GODOY, A. S. Introdução à Pesquisa Qualitativa e suas Possibilidades. RAE-Revista de Administração de Empresas, v. 35, n. 2, mar.-abr., 1995, p. 57-63. Disponível em: http://biblioteca digital.fgv.br/ojs/index.php/rae/article/download/38183/36927.>. Acesso em: 06 ago. 2017. 
RINALDI, R. P. Desenvolvimento Profissional de Formadores em Exercício: contribuições de um programa on-line. 2009. 231f. Tese (Doutorado em Educação) - Universidade Federal de São Carlos - UFSCar, São Carlos.

FRANCO, M. L. P. B. Análise de Conteúdo. 4 ed. Brasília: Liber Livro, 2012.

IMBERNÓN, F. Formação Continuada de professores. Tradução: Juliana dos Santos Padilha. Porto Alegre: Artmed, 2010. 